\title{
Hypertrophic scars in a patient with Turner's syndrome treated with recombinant growth hormone
}

\author{
Andrzej Kędzia' ${ }^{1}$ Mariola Pawlaczyk² ${ }^{2}$ Elżbieta Petriczko³ \\ 1Department of Clinical Auxology and Pediatric Nursing, Poznan University of Medical Sciences, Poznan, Poland \\ Head of Department: Ass. Prof. Andrzej Kędzia \\ 2Department of Geriatric Medicine and Gerontology, Division of Skin Diseases Prophylaxis, Poznan University of Medical Sciences, \\ Poznan, Poland \\ Head of Department: Ass. Prof. Mariola Pawlaczyk \\ ${ }^{3}$ Clinic of Pediatrics, Endocrinology, Diabetology, Metabolic Diseases and Cardiology of the Children, Pomeranian Medical University, \\ Szczecin, Poland \\ Head of Clinic: Prof. Mieczysław Walczak MD, PhD
}

Postep Derm Alergol 2014; XXXI, 2: 117-120

DOI: 10.5114/pdia.2014.40917

\begin{abstract}
Turner's syndrome is a common genetic disorder of girls and women, for which characteristic clinical symptoms encompass short stature, gonadal dysgenesis, systemic defects, multiple dysmorphic features and skin changes, including an increased number of melanocytic nevi, hypertrophic scars and keloids. The affected girls are treated with recombinant human growth hormone to improve the height. We present a case of a 15-year-old girl with Turner's syndrome, hypertrophic scars and a keloid. At the age of 12 years and 8 months, the girl started recombinant human growth hormone treatment. During the therapy, a surgical excision of 4 out of 42 benign melanocytic nevi was performed. After 2 months the hypertrophic scars as well as a keloid were noted at sites of excision. Parents of girls with Turner's syndrome undertake various attempts to improve not only the height and maturity of their daughters, but also their appearance by commonly performed surgical corrections of the webbed neck and pigmented nevi. The presented case suggests an increased risk of scars hypertrophy and keloid formations after surgical intervention in Turner's syndrome patients who are treated with recombinant human growth hormone at the same time. Due to that it should be advised to postpone all planned surgical procedures until the therapy has been completed.
\end{abstract}

Key words: Turner's syndrome, scar, hypertrophy, growth hormone.

\section{Introduction}

Turner's syndrome (TS) is a genetic disorder diagnosed on the basis of the analysis of $45, \mathrm{X}$ karyotype or mosaics including cells with that karyotype. The reported incidence of TS varies from 1 in 2000 to 1 in 5000 live female births [1, 2]. The syndrome manifests itself in a number of ways. Girls with TS typically experience short stature and gonadal dysgenesis. Apart from congenital systemic defects (mostly cardiovascular and of the urinary tract), TS patients present with multiple dysmorphic features, including webbed neck, high-arch palate, cubitus valgus, shield chest with widely spaced nipples, short $4^{\text {th }}$ and $5^{\text {th }}$ metacarpals. Skin manifestations, including lower extremity lymphedema in children, low hairline, abnormal fingernails, pigmented nevi (increasing in number with age) [3-6] and a tendency to develop hypertrophic scars and keloids [6-8], constitute other characteristic features of Turner's syndrome. Recombinant human growth hormone (rhGH) treatment aims at improving the height of affected girls [9].

The presented case raises a question of increased risk of hypertrophic scarring and keloids after surgical intervention in TS patients during rhGH treatment.

\section{Case report}

We present a case of a 15 -year-old TS patient, $45, \mathrm{X}$ karyotype, treated at the Department of Clinical Auxology since 2010. In 2012, during the routine follow-up the patient was diagnosed with hypertrophic scars and a keloid after the surgical excision of melanocytic nevi. At the age of 12 years and 8 months and at the height of $139 \mathrm{~cm}$, the girl started rhGH treatment, daily injections with an average dose of $0.331 \mathrm{mg} / \mathrm{kg}$ b.w./week. Upon first admission

Address for correspondence: Mariola Pawlaczyk MD, PhD, Department of Geriatric Medicine and Gerontology, Division of Skin Diseases Prophylaxis, Poznan University of Medical Science, 34 Dojazd St, 60-631 Poznan, Poland, phone: +48 61601747670 ,

e-mail: mariolapawlaczyk@o2.pl

Received: 21.04.2013, accepted: 23.05.2013. 
to the clinic, before rhGH treatment, her physical examination revealed short stature, webbed neck, shield chest with wide nipples, cubitus valgus, high-arch palate, bone age 11 years, Tanner 1 genital and pubic hair, Tanner stage 3 thelarche. Endocrine examinations excluded other reasons for growth retardation and her mental development was normal. No other systemic failures were found. Before the treatment commencement, dermatological evaluation revealed 42 pigmented nevi (regular shape, 3-5 $\mathrm{mm}$ diameter) on the skin of the face, trunk and extremities. As dermoscopic examination confirmed the lesions to be benign, no surgical excision was recommended. At the age of 14, 10 months after the treatment with rhGH started, 4 of the largest congenital nevi were surgically removed (the parents of the patient claimed the changes had grown in size) without consulting the attending physician. After 2 months all postoperative scars were hypertrophic. The scars in the left preauricular area (Figure 1), on the nucha beneath hairline (Figure 2) and on the left arm (Figure 3) remained hypertrophic but the scar on the back (Figure 4) turned into a keloid. Serum concentrations of insulin-like growth factor (IGF-I) and insulin like-growth factor-binding protein 3 (IGFBP-3) were examined at the beginning of the treatment and after 12 months. The results are presented in Table 1, compared with concentrations found in a group of 26 other TS patients and of 32 patients with GH deficit (GHD), treated with the same medications at an average dose of 0.330-0.334 mg/kg b.w./week and 0.170-0.176 $\mathrm{mg} / \mathrm{kg}$ b.w./week, respectively. The analysis of IGF-I and IGFBP-3 serum concentrations in the presented case did not reveal significant differences in comparison to parameters of other girls treated for short stature.

\section{Discussion}

Hypertrophic scars (HS) and keloids (K) are a result of an excessive fibroblast production, particularly collagen, with absence of increased collagenase activity [10]. Lowenstein et al. described them among other skin stig-

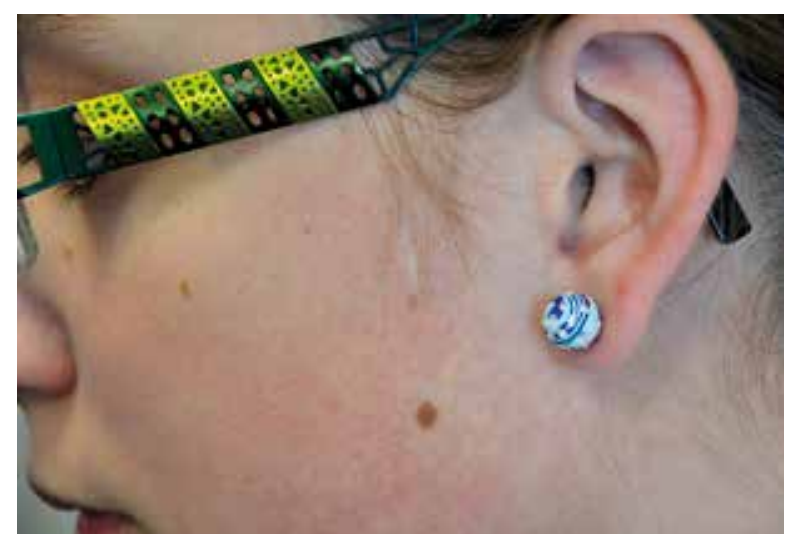

Figure 1. Hypertrophic scar on the left preauricular area and melanocytic nevi on the left cheek mata in patients with TS but questioned their common occurrence [6]. Nevertheless, keloids after surgical correction of the webbed neck have been reported [7, 8, 11]. The difference between hypertrophic scars and keloids lies in the fact that the former are thickened but confined to the margins of the injury site, while the latter migrate over the initial wound site. Nevertheless, differentiation may still be challenging [10]. Hypertrophic scars develop due to excessive collagen type III production, which is localized alongside nodules containing myofibroblasts and large collagen fibers and its reduced use. Keloid tissue is composed of unorganized collagen type I and III. None of the lesions contain elastic fibers, hair follicles, sebaceous and sweat glands [12]. Huang et al. are of the opinion that hypertrophic scars and keloids are stages of the same skin disease connected with fibroblast growth, what was confirmed by histopathological examinations of lesions [13]. Hypertrophic scars and keloids occur in all age groups, although sporadically in children and the elderly. They may be found in various localizations but are relatively rare on the eyelids, central part of the face or genital organs [10]. Recombinant human, as well as the endogenous, growth hormone causes IGF-I accumulation. Insulin-like growth factor affects the tissues directly and causes intensification of cell division. Receptors for $\mathrm{GH}$ and IGF-I have been found in cells of numerous tumors, for example of the brain, breast, colon, and others. The issue whether high concentrations of IGF-I in fact trigger the development of de novo neoplastic lesions or only stimulate the growth of existing tumors is currently being investigated [14]. Hypertrophic scars and keloids are considered benign tumors whose pathomechanism remains not fully elucidated. The role of genetic factors, apoptosis, endogenous factors (nitric oxide), growth factors, cytokine and exogenous factors (oxygen deficiency and diet) is emphasized [10, 12, 13]. Insulin-like growth factor is also mentioned among many other growth factors that influence the development of both scar abnormalities $[15,16]$, what might support the connection

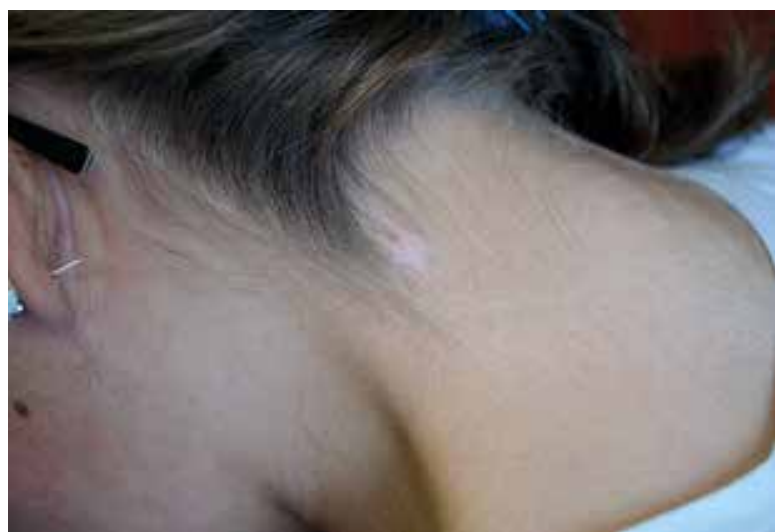

Figure 2. Hypertrophic scar on the nucha beneath the low hairline 


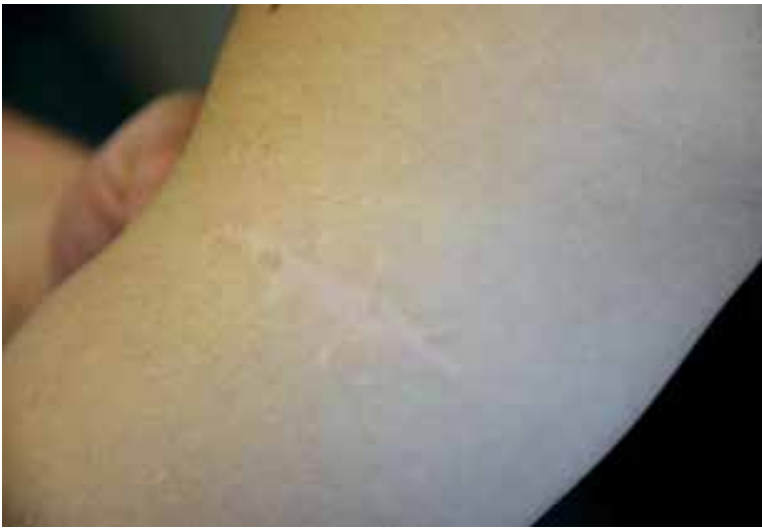

Figure 3. Hypertrophic scar on the left arm

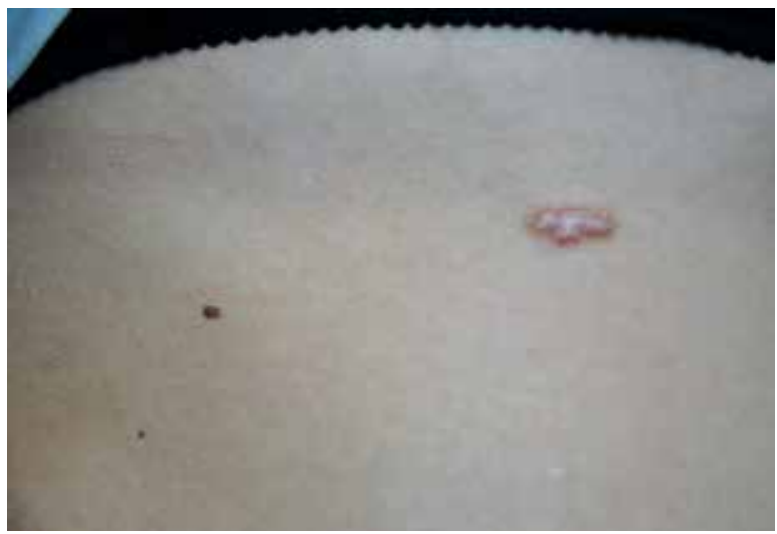

Figure 4. Keloid on the back and two melanocytic nevi

Table 1. Comparison of mean IGF-I and IGFBP-3 concentrations and the rate of growth between the presented TS case and relevant groups

\begin{tabular}{|c|c|c|c|}
\hline Studied patients & $\begin{array}{l}\text { Mean IGF-I concentrations } \\
\text { SDS (value range) }\end{array}$ & $\begin{array}{c}\text { Mean IGFBP-3 } \\
\text { concentration } \\
\text { SDS (value range) }\end{array}$ & $\begin{array}{l}\text { Mean growth rate } \\
\text { [cm/year] }\end{array}$ \\
\hline TS patient with hypertrophic scars & $+1.43(-0.6$ to +3.2$)$ & $+2.3(+1.8$ to +2.4$)$ & 4.86 (3.2 to 7.0$)$ \\
\hline 26 TS patients & $+1.62(-1.5$ to +5.5$)$ & $+2.34(+1.5$ to +2.8$)$ & 5.70 (3.4 to 9.4$)$ \\
\hline 32 GHD patients & $+0.059(-2.6$ to +5.4$)$ & $+1.47(+1.0$ to +2.0$)$ & 7.62 (3.6 to 10.4$)$ \\
\hline
\end{tabular}

SDS - standard deviation score

between the occurrence of the lesions in our patient and the rhGH therapy.

Treatment of TS patients requires 100\% higher doses of rhGH than of patients with GHD, while bearing in mind their preserved endogenous secretion of the growth hormone. The question remains whether such large doses of rhGH overlapping with its own secretion will not cause a significant increase in the IGF-I concentration. Maintaining high concentrations of IGF-I in TS patients might have an adverse effect not only on the risk of neoplastic progression, but also on many other aspects connected with the disease. The analysis in Table 1 shows that IGF-I accumulation in girls with TS treated with rhGH is significantly higher than in same sex peers treated for GHD, where IGF-I concentrations merely reach the values close to healthy population reference values, what might be a cause for concern. On the other hand, the concentrations of the IGFBP-3 carrier protein in TS patients are also significantly elevated, up to 2.3 SDS, what seems to have a protective role against mitotic activity of high concentrations of free IGF-I. However, the comparison of the two groups of patients reveals that in the case of GHD, an increased concentration of IGF-I (to the ranges no more than close to the normal values in healthy girls) is accompanied by a smaller (reaching max. 1.5 standard deviation) increase in IGFBP-3. The analysis of the ratio between IGF-I and IGFBP-3 for TS and GHD patients revealed it to be 0.69 and 0.04 , respectively. Thus, TS is characterized by a significantly higher concentration of IGF-I and lower concentration of IGFBP-3 than GHD.

Numerous melanocytic nevi occur in TS patients significantly more often than in healthy populations. Nevi are usually benign, from $1 \mathrm{~mm}$ to $5 \mathrm{~mm}$ in diameter, with no dysplastic features in the clinical and histopathologic profile $[3,17,18]$, like in our case. Large atypical lesions are rare in the course of TS [5]. Growth hormone treatment was suspected to contribute to the enlargement of the pigmented nevi but further clinical observations did not confirm that hypothesis [19-21].

Small melanocytic nevi do not increase the risk of melanoma, thus there is no need of immediate surgical intervention in these cases. Excision of pigmented nevi ought to be performed after puberty because neoplastic transformation rarely occurs earlier than that [22]. That rule should apply especially to TS patients treated with $\mathrm{GH}$, whose lesions need to be observed and monitored by means of dermoscopy but not removed. Due to high difficulty and low efficiency of hypertrophic scars and keloids treatment, this management is at the same time prophylactic manner of their development.

Parents of girls with TS undertake various attempts to improve not only the height and maturity of their 
daughters, but also their appearance by commonly performed surgical corrections of the webbed neck and pigmented nevi. Due to the risk of stretching of the postsurgical scars caused by the process of growth, they should be advised to postpone these attempts until the rhGH treatment has been completed.

\section{Conflict of interest}

All authors declare no conflict of interest.

\section{References}

1. Hook E, Warburton D. The distribution of chromosomal genotype associated with Turner's syndrome: live birth prevalence rates and evidence for diminished fetal mortality and severity in genotypes associated with structural $X$ abnormalities or mosaicism. Hum Genet 1983; 64: 24-7.

2. Gibbs P, Brady B, Gonzalez R, Robinson W. Nevi and melanoma: lessons from Turner's syndrome. Dermatology 2001; 202: 1-3.

3. Becker B, Jospe N, Goldschmith L. Melanocytic nevi in Turner's syndrome. Pediatr Dermatol 1994; 11: 120-4.

4. Boroni G, Larizza D, Vignatti G. The dermatologic spectrum of Turner syndrome. J Eur Acad Dermatol Venereol 1994; 3: 334-40.

5. Zvulunov A, Wyatt D, Laud P, Esterly N. Influence of genetic and environmental factors on melanocytic naevi: a lesson from Turner's syndrome. Br J Dermatol 1998; 138: 993-7.

6. Lowenstein EJ, Kim KH, Gluck SA. Turner's syndrome in dermatology. J Am Acad Dermatol 2004; 50: 767-76.

7. Hall J, Gilchrist D. Turner syndrome and its variants. Pediatr Clin North Am 1990; 37: 1421-40.

8. Lemli L, Smith D. The XO syndrome: a study of the differentiated phenotype in 25 patients. J Pediatr 1963; 63: 577-88.

9. Ross JL, Quigley CA, Cao D, et al. Growth hormone plus childhood low-dose estrogen in Turner syndrome. N Engl J Med 2011; 31: 1230-42.

10. Bolognia JL, Lorizzo JL, Rapini RP, et al. Dermatology. Elsevier Mosby Ltd. 2008; 1497-9.

11. Larralde M, Gardner SS, Torrado MV, et al. Lymphedema as a postulated cause of cutis verticis gyrata in Turner syndrome. Pediatr Dermatol 1998; 15: 18-22.

12. Slemp AE, Kirschner RE. Keloid and scars: review of keloids and scars, their pathogenesis, risk factors and management. Curr Opin Pediat 2006; 18: 396-402.

13. Huang C, Akaishi S, Hyakusoku H, Ogawa R. Are keloid and hypertrophic scar different forms of the same disorder? A fibroproliferative skin disorder hypothesis based on keloid findings conditions. Int Wound I 2012 Nov 22. doi: 10.1111/j.1742-481X.2012.01118.x

14. Rosen CJ, Pollak M. Circulating IGF-I: new perspectives for a new century. Trends Endocr Metab 1999; 10: 136-41.

15. Yoshimoto $\mathrm{H}$, Ishihara $\mathrm{H}$, Ohtsuru A. Overexpression of insulin-like growth factor-1 (IGF-I) receptor and the invasiveness of cultured keloid fibroblasts. Am J Pathol 1999; 154: 883-9.

16. Phan TT, Lim IJ, Bay BH, et al. Role of IGF system of mitogens in the induction of fibroblast proliferation by keloid-derived keratinocytes in vitro. Am J Physiol Cell Physiol 2003; 284: c860-9.

17. Bourguignon J, Pierard G, Ernould C, et al. Effects of human growth hormone therapy on melanocytic naevi. Lancet 1993; 341: 1505-6.
18. Pierard G, Pierard-Franchimont C, Nikkels A, et al. Naevocyte triggering by recombinant human growth hormone. J Pathol 1996; 180: 74-9.

19. Zvulunov A, Wyatt D, Laud P, Esterly N. Lack of effect of growth hormone therapy on the count and density of melanocytic naevi in children. Br J Dermatol 1997; 137: 545-8.

20. Zvulunov A, Wyatt D, Rabinowitz L, Esterly N. Effect of growth hormone therapy on melanocytic nevi in survivors of childhood neoplasia. Arch Dermatol 1997; 133: 795-6.

21. Wyatt D. Melanocytic nevi in children treated with growth hormone. Pediatrics 1999; 104: 1045-50.

22. Noto G. On the clinical significance of cutaneous melanoma's precursors. Indian Dermatol Online J 2012; 3: 83-8. 